ARTICLE

\title{
Catalytic asymmetric Nakamura reaction by gold(I)/chiral N,N'-dioxide-indium(III) or nickel(II) synergistic catalysis
}

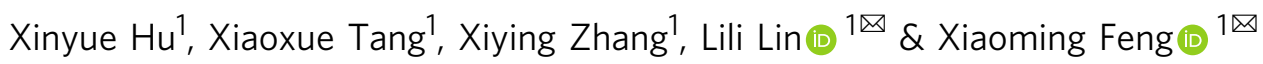

Intermolecular addition of enols and enolates to unactivated alkynes was proved to be a simple and powerful method for carbon-carbon bond formation. Up to date, a catalytic asymmetric version of alkyne with 1,3-dicarbonyl compound has not been realized. Herein, we achieve the catalytic asymmetric intermolecular addition of 1,3-dicarbonyl compounds to unactivated 1-alkynes attributing to the synergistic activation of chiral $N, N^{\prime}$-dioxide-indium (III) or nickel(II) Lewis acid and achiral gold(I) $\pi$-acid. A range of $\beta$-ketoamides, $\beta$-ketoesters and 1,3-diketones transform to the corresponding products with a tetra-substituted chiral center in good yields with good e.r. values. Besides, a possible catalytic cycle and a transition state model are proposed to illustrate the reaction process and the origin of chiral induction based on the experimental investigations.

\footnotetext{
${ }^{1}$ Key Laboratory of Green Chemistry \& Technology, Ministry of Education, College of Chemistry, Sichuan University, Chengdu, China. ${ }^{\circledR}$ email: lililin@scu.edu.cn; xmfeng@scu.edu.cn
} 
$\mathrm{T}$ he addition of carbonyl compounds without prior enolate formation to unactivated alkynes is an attractive and atom economical method for carbon-carbon bond formation ${ }^{1}$. It results in the introduction of a vinyl substituent to vicinal position of carbonyl groups, possessing an important role in organic synthesis of natural products and drugs ${ }^{2-5}$. The intramolecular type, which is known as the Conia-ene reaction, generating cycloalkene derivatives, has achieved significant progress. Besides the well-developed non-enantioselective systems ${ }^{6-11}$, catalytic asymmetric Conia-ene reactions have already been realized by synergistic hard/soft Lewis acid catalysts (e.g., $\mathrm{Pd} / \mathrm{Yb}, \mathrm{Yb} / \mathrm{Zn}$, $\mathrm{Ag} / \mathrm{La}, \mathrm{Ag} / \mathrm{Fe})^{12-15}$, Lewis basic amine/Lewis acid catalysts (e.g., $\mathrm{Cu}, \mathrm{Ag}$-based) ${ }^{16-19}$, and Brønsted basic amine/Lewis acid catalyst $\left(\mathrm{B}\left(\mathrm{C}_{6} \mathrm{~F}_{5}\right)_{3} / \mathrm{Zn} / \mathrm{PMP}\right)^{20}$. In contrast, the intermolecular reaction of 1,3-dicarbonyl compounds to unactivated 1-alkynes (Nakamura reaction) was less developed. Such a process is unviable because of the unfavorable thermodynamics that there is a high-lying LUMO of an unactivated alkyne compared to the HOMO of 1,3-dicarbonyl compounds 21,22 . In 2003 , Nakamura et al. documented an indium-catalyzed addition of 1,3-dicarbonyl compounds to unactivated 1-alkynes ${ }^{23}$, providing an efficient synthetic route to form 2-alkenyl-1,3-dicarbonyl compounds from abundant carbon alkynes sources. After that, In(III $)^{24-28}, \operatorname{Re}(\mathrm{I})^{29-31}$, Ir $(\mathrm{I})^{32}, \mathrm{Pd}(0)^{33}, \mathrm{Co}(\mathrm{II})^{34}, \mathrm{Mn}(\mathrm{I})^{35,36}$, and $\mathrm{Ru}(\mathrm{I})$-(III) ${ }^{37-39}$ catalytic systems were discovered, all of which were racemic reports except for only one example using substrates with chiral auxiliary ${ }^{40}$. All the above reports, the dicarbonyl compounds and alkynes need to be activated simultaneously. Beyond that, the Shi group reported a synergistic $\mathrm{Au}(\mathrm{I}) / \mathrm{Ga}(\mathrm{III})$ catalysis in Nakamura reaction ${ }^{41}$, in which $\mathrm{Au}(\mathrm{I})$ activated the alkynes whereas $\mathrm{Ga}(\mathrm{III})$ enhanced the acidity of the 1,3-dicarbonyl compounds ${ }^{42,43}$, affording racemic 2-alkenyl-1,3-dicarbonyl products. Generally, all the Nakamura reactions were still limited to racemic examples (Fig. 1).

Therefore, developing an efficient catalytic system to realize the asymmetric version of the Nakamura reaction is challenging but highly desirable.

a) Catalytic asymmetric Conia-ene reaction (intramolecular, cyclised products)

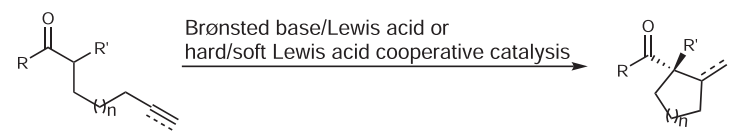

by Toste, Shibasaki, Dixon, Shibata, White

b) Nakamura reaction (intermolecular, chain products):

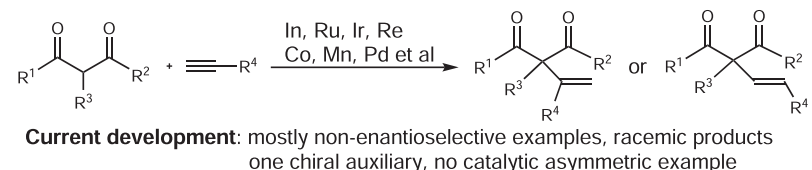

c) This work:

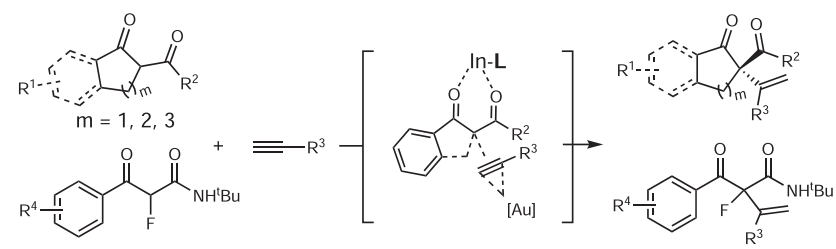

- Catalytic asymmetric Nakamura reaction

- Chiral 2-alkenyl-carbonyl compounds with a chiral all-carbon quaternary center

or acyclic centre with a fluorine substituent

- High enantioselectivity

Fig. 1 The catalytic asymmetric addition of 1,3-dicarbonyl compounds to alkynes. a Catalytic asymmetric Conia-ene reaction. $\mathbf{b}$ Development of Nakamura reaction. c Our strategies for the catalytic asymmetric Nakamura reaction.
Bimetallic catalysis is also promising in asymmetric catalysis ${ }^{44-46}$ However, one of the perceived challenges is that two distinct metals might competitively coordinate with the ligand, as well as potentially affect each other's catalytic cycles. Recently, chiral $N, N^{\prime}$-dioxides/hard Lewis acid complexes developed by our group were found to be good partners with soft metals ${ }^{47-51}$ in relay catalysis systems. We envisioned that $N, N^{\prime}$-dioxide/Lewis acid complex could also be applied to synergistic catalyst system.

In this work, we developed a gold(I)/chiral $N, N^{\prime}$-dioxideindium(III) or nickel(II) synergistic catalyst system to realize the catalyic asymmetric Nakamura reaction of unactivated 1-alkynes with $\beta$-ketoamides, $\beta$-ketoesters, and 1,3-diketones in good reactivity and enantioselectivity. Mechanism study elucidates the process of the reaction and origin of chiral induction.

\section{Results}

Optimization of the reaction conditions. Indanone-derived $\beta$ ketoamide $\mathbf{1 a}$ and phenylacetylene $\mathbf{2 a}$ were selected as the model substrates to conduct our research. First, several cooperative catalytic systems, which showed good ability in catalytic enantioselective Conia-ene reaction, including $\mathrm{Pd}(\mathrm{II}) / \mathrm{Yb}(\mathrm{III})$ dual catalyst system, $\mathrm{Zn}(\mathrm{II}) / \mathrm{Yb}$ (III) catalyst system, and amine-silver system, were investigated ${ }^{13,16,19}$. But all of them gave only trace amount of product without enantioselectivities even rising the reaction temperature to $70^{\circ} \mathrm{C}$ (Table 1 , entries 1-3). Then chiral $N, N^{\prime}$-dioxide ligand-metal complexes were chosen as the activators of ketoamides, in connection with $\mathrm{AuCl} \cdot \mathrm{PPh}_{3} / \mathrm{AgOTf}$ for the activation of 1-alkyne. First, $\mathrm{Sc}(\mathrm{OTf})_{3}$ was used to coordinate with chiral $N, N^{\prime}$-dioxide $\mathbf{L}-\mathbf{P i E t}_{2}$ to promote the reaction under air atmosphere, the byproduct $3 \mathbf{b b}$ was obtained as the main product along with the desired product 3aa in 11\% yield with 60:40 e.r. (entry 4). Further research showed that the reaction could possess efficiency in an absolute anaerobic condition, delivering the product 3aa in $92 \%$ yield with 60:40 e.r. (entry 5). Then $\mathrm{Ga}(\mathrm{OTf})_{3}$ that showed efficient catalytic activity in Shi's report ${ }^{41}$ was used to coordinate with chiral $N, N$ '-dioxide $\mathbf{L}-\mathbf{P i E t}_{2}$ to promote the reaction; however, only trace of product 3aa was obtained (entry 6). To our delight, $\operatorname{In}(\mathrm{OTf})_{3}$ could improve the reaction activity greatly and deliver the desired product with 62:38 e.r. (entry 7). The ligand L-TQ-(S)-EPh derived from $S$-tetrahydroisoquinoline acid decreased the e.r. greatly (entry 8 ). To improve the enantioselectivity, other conditions were carefully studied. Changing the $N, N^{\prime}$-dioxide ligand to $\mathbf{L}-\mathbf{P i E t}_{2} \mathbf{M e}$, which has ethyl groups at ortho-positions and methyl group at para-position of aniline, the yield could be improved to $99 \%$ (entry 9 ). Moreover, the addition of trace amount of $\mathrm{H}_{2} \mathrm{O}$ (entry 10) and increasing the amount of ligand $\mathbf{L}-\mathbf{P i E t}_{2} \mathbf{M e}$ (entry 11) improved the enantioselectivity. The water might be beneficial for formation of the effective catalyst species, as well as beneficial for accelerating the enolization of 1,3 dicarbonyl compounds ${ }^{52}$. Meanwhile, the increasement of ligand might be helpful for the complete coordination with $\operatorname{In}(\mathrm{OTf})_{3}$, avoiding the strong background reaction caused by free metal salt. Further exploration showed that the solvent had a great influence on the reaction, when para-xylene was used as the solvent, the desired product was isolated in 98\% yield with 90:10 e.r. (entry 12). The enantioselectivity enhanced into 94.5:5.5 e.r. after the concentration of 1 a reduced to $0.067 \mathrm{~mol} / \mathrm{L}$ by enhancing the amount of solvent (entry 13). The steric hindrance of the ligands on $[\mathrm{Au}]$ catalyst was another key factor. Changing the $\mathrm{AuCl} \cdot \mathrm{PPh}_{3}$ into more sterically hindered XPhosAu(TA)OTf, only trace product could be obtained (entry 14). The reason might be that the bulky X-Phos cause larger steric hindrance between the [Au]-activated 1-alkyne and the chiral Lewis acid-activated 1,3dicarboyl compound, making the reaction happen more difficultly. In comparison, other indium catalysts of the typical chiral 
Table 1 Optimization of the reaction conditions.

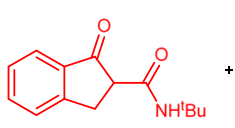

$1 \mathrm{a}$<smiles>Pc1ccc2c(c1-c1cccc3c1OCO3)OCO2</smiles>

L1: (R)-DTBM-SEGPHOS $\mathrm{Ar}=3,5-\mathrm{tBu}_{2}-4-\mathrm{MeC}_{6} \mathrm{H}_{2}$

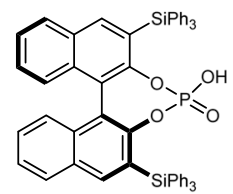

L5: CPA

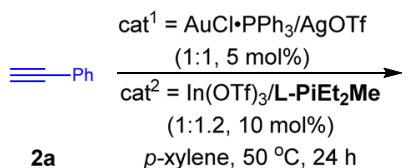

p-xylene, $50^{\circ} \mathrm{C}, 24 \mathrm{~h}$

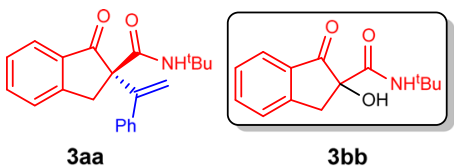

3aa

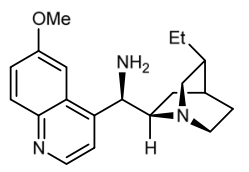

L4: quinidine amine

L2: tBu-Box<smiles>c1ccc([C@H]2COC(c3cccc(C4=N[C@@H](c5ccccc5)CO4)n3)=N2)cc1</smiles>

L3: Ph-Pybox<smiles></smiles>

L-PiEt $t_{2}: R=2,6-\mathrm{Et}_{2} \mathrm{C}_{6} \mathrm{H}_{3}$

L-PiEt ${ }_{2} \mathrm{Me}: \mathrm{R}=2,6-\mathrm{Et}_{2}-4-\mathrm{MeC}_{6} \mathrm{H}_{2}$

L-PiMe ${ }_{3}: R=2,4,6-\mathrm{Me}_{3} \mathrm{C}_{6} \mathrm{H}_{2}$

L-PiMe $2: R=2,6-\mathrm{Me}_{2} \mathrm{C}_{6} \mathrm{H}_{3}$<smiles>[R]N1[CH]O[N+]2(CCC[N+]34Cc5ccccc5C[C@H]3C(=O)N([R])Cc3ccccc3C4)OCN([R])C(=O)[C@@H]2C1</smiles>

L-TQ-(S)-EPh: R = (s)-2-phenylethyl

\begin{tabular}{|c|c|c|c|}
\hline Entry & Variation from the "standard conditions"a & Yieldb (\%) & e.r.c \\
\hline 1 & cat $^{1}:$ L1/Pd(OTf) $2,(10 \mathrm{~mol} \%)$, cat $^{2}: \mathrm{Yb}(\mathrm{OTf})_{3}(20 \mathrm{~mol} \%), \mathrm{AcOH}(10$ equiv $)$, mesitylene $(5.0 \mathrm{~mL}), 48 \mathrm{~h}$ & n.r. & - \\
\hline $2^{d}$ & cat $^{1}: \mathbf{L 2} / \mathrm{Zn}(\mathrm{OTf})_{2},(1: 1.1,10 \mathrm{~mol} \%) \mathrm{cat}^{2}: \mathrm{Yb}(\mathrm{OTf})_{3}(20 \mathrm{~mol} \%)$, HFIP (1 equiv), mesitylene $(1.0 \mathrm{~mL}), 70^{\circ} \mathrm{C}$ & Trace & $50: 50$ \\
\hline 3 & cat?: AgOTf, (2.5 mol\%), cat²: L4 (20 mol\%), TFA (20 mol\%), mesitylene, $48 \mathrm{~h}$ & n.r. & - \\
\hline $4^{e}$ & cat$^{2}: \mathbf{L - P i E t} \mathbf{z}_{\mathbf{2}} / \mathrm{Sc}(\mathrm{OTf})_{3}(1: 1), \mathrm{DCE}$ & 11 & $60: 40$ \\
\hline 5 & cat $^{2}: \mathbf{L}_{-} \mathbf{P i E t}_{\mathbf{2}} / \mathrm{Sc}(\mathrm{OTf})_{3}(1: 1), \mathrm{DCE}$ & 92 & $60: 40$ \\
\hline 6 & cat $^{2}:$ L-PiEt $\mathbf{2} / \mathrm{Ga}(\mathrm{OTf})_{3}(1: 1), \mathrm{DCE}$ & Trace & - \\
\hline 7 & cat $^{2}:$ L-PiEt $\mathbf{2} / \ln (\mathrm{OTf})_{3}(1: 1), \mathrm{DCE}$ & 98 & $62: 38$ \\
\hline 8 & cat $^{2}$ : L-TQ-(S)-EPh/In(OTf) $3,(1: 1)$, DCE & 94 & $56.5: 43.5$ \\
\hline 9 & cat $^{2}: \mathbf{L}-\mathbf{P i E t}_{\mathbf{2}} \mathbf{M e} / \operatorname{In}(\mathrm{OTf})_{3}(1: 1), \mathrm{DCE}$ & 99 & $63: 37$ \\
\hline 10 & cat $^{2}: \mathbf{L}-\mathbf{P i E t}_{\mathbf{2}} \mathbf{M e} / \operatorname{In}(\mathrm{OTf})_{3}(1: 1), \mathrm{H}_{2} \mathrm{O}(2 \mu \mathrm{L}), \mathrm{DCE}$ & 99 & $65: 35$ \\
\hline 11 & $\mathrm{H}_{2} \mathrm{O}(2 \mu \mathrm{L}), \mathrm{DCE}$ & 98 & $70: 30$ \\
\hline 12 & $\mathrm{H}_{2} \mathrm{O}(2 \mu \mathrm{L})$ & 98 & $90: 10$ \\
\hline 13 & $\mathrm{H}_{2} \mathrm{O}(2 \mu \mathrm{L}), p$-xylene $(1.5 \mathrm{~mL})$ & 98 & $94.5: 5.5$ \\
\hline 14 & cat ${ }^{1}:$ XPhosAu(TA)OTf/AgOTf, $\mathrm{H}_{2} \mathrm{O}(2 \mu \mathrm{L})$, -xylene $(1.5 \mathrm{~mL})$ & Trace & - \\
\hline 15 & cat $^{2}: \mathbf{L} \mathbf{3} / \ln (\mathrm{OTf})_{3}, p$-xylene $(1.5 \mathrm{~mL})$ & 13 & $47: 53$ \\
\hline 16 & cat $^{2}: \mathbf{L} 2 / \ln (\mathrm{OTf})_{3,}$-xylene $(1.5 \mathrm{~mL})$ & 5 & $50: 50$ \\
\hline 17 & cat $^{2}:$ L5, $p$-xylene $(1.5 \mathrm{~mL})$ & 8 & $50: 50$ \\
\hline \multicolumn{4}{|c|}{ 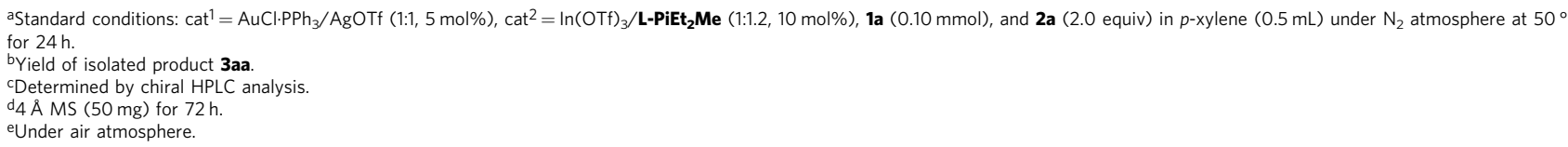 } \\
\hline
\end{tabular}

ligands such as Pybox L3, Box L2, or CPA organocatalyst were used, the product 3aa was obtained in low yield with poor e.r. value (entries 15-17).

Substrate scope of the reaction about $\boldsymbol{\beta}$-ketoamides. With the optimized reaction conditions in hand (Table 1, entry 13), the substrate scope was then evaluated (Fig. 2). A variety of ketoamides 1 derived from 1-indanones with different substituents were tested. Substrates with electron-donating groups exhibited excellent yields and enantioselectivities (3ba-3ea) at $50{ }^{\circ} \mathrm{C}$. Substrate 1f bearing an electron-withdrawing group transformed to the desired product $3 \mathbf{f a}$ in $98 \%$ yield with $85: 15$ e.r. at higher temperature $\left(60^{\circ} \mathrm{C}\right)$. With respect to 1 -alkynes 2 , when the substituents at the aromatic ring of the phenylacetylenes varied, both steric hindrance and electronic properties had little effect on the reaction (3ab-3ai). However, substrate 1,4-diethynylbenzene $2 \mathbf{j}$ just delivered the product 3aj in moderate yield with excellent enantioselectivity. It might be caused by the competitive coordination of the alkyne-bearing product with AuOTf $\mathrm{PPh}_{3}$. The thienyl-substituted alkynes (2k and $\mathbf{2 l}$ ) were also suitable. Various aliphatic 1-alkynes (2m-2q) could also transform to the desired products in good enantioselectivities (3am-3aq); however, the yield was generally moderate. One reason is that an unidentified product generated that might be caused by In(III)-induced olefin isomerization $^{41}$. Importantly, the methodology was applicable to the alkyl-alkyne derived from saccharide 2r. Next, ring structure of ketoamides was studied. The substrate $\mathbf{1 h}$ derived from 1-tetralone got good results (3ha-3hm), while $\mathbf{1 i}$ derived from 1-benzosuberone gave much lower yield and e.r.. It might be caused by steric hindrance between methylene of substrate 1i with AuOTf.PPh $\mathrm{Ph}_{3}$-activated 2a. Meanwhile, aliphatic substrate 1j 


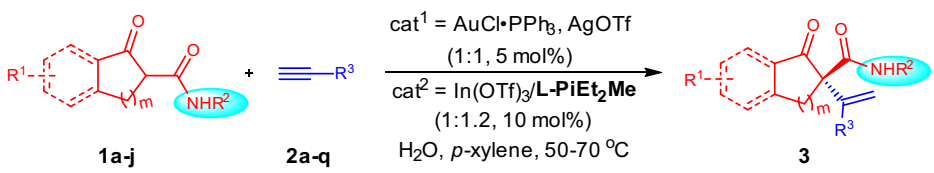

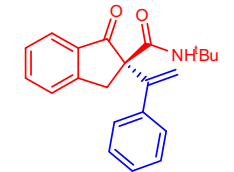

(R)-3aa, $50{ }^{\circ} \mathrm{C}, 24 \mathrm{~h}$ $98 \%$ yield, $94.5 .5 .5 e$

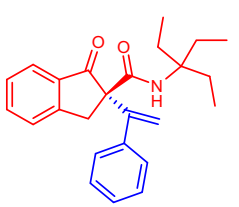

(R)-3ga ${ }^{\mathrm{a}}, 50{ }^{\circ} \mathrm{C}, 24 \mathrm{~h}$ $98 \%$ yield, $90: 10$ e.r.

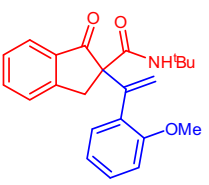

3af, $50^{\circ} \mathrm{C}, 24 \mathrm{~h}$ $99 \%$ yield, $92: 8$ e.r.

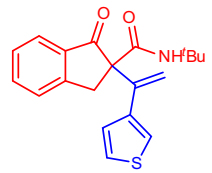

$3 \mathrm{al}, 50{ }^{\circ} \mathrm{C}, 24 \mathrm{~h}$ $99 \%$ yield, $94.5: 5.5 e$.

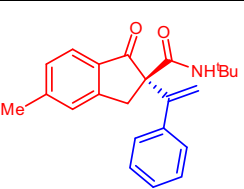

(R)-3ba, $50^{\circ} \mathrm{C}, 24 \mathrm{~h}$
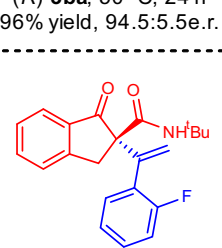

(R)-3ab, $60^{\circ} \mathrm{C}, 48 \mathrm{~h}$ $94 \%$ yield, $92: 8$ e.r.

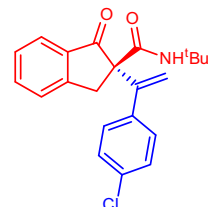

(R)-3ag, $60{ }^{\circ} \mathrm{C}, 72 \mathrm{~h}$ $93 \%$ yield, $93.5: 6.5$ e.r.

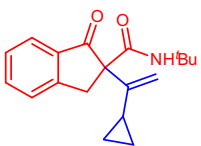

3 am $50^{\circ} \mathrm{C}, 48 \mathrm{~h}$ $68 \%$ yield, $89.5: 10.5$ e.r.

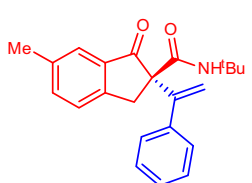

(R)-3ca, $50^{\circ} \mathrm{C}, 24 \mathrm{~h}$ $99 \%$ yield, $95: 5$ e.r.

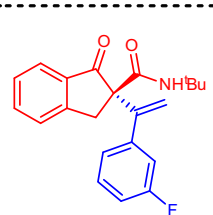

(R)-3ac, $60{ }^{\circ} \mathrm{C}, 72 \mathrm{~h}$ $89 \%$ yield, 93.5:6.5e.r.

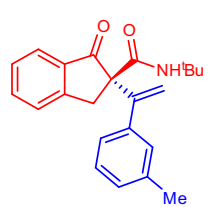

(R)-3ah, $50{ }^{\circ} \mathrm{C}, 24 \mathrm{~h}$ $99 \%$ yield, $93: 7$ e.r.

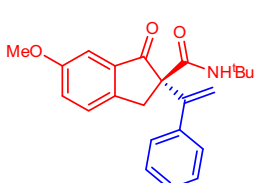

(R)-3da, $50{ }^{\circ} \mathrm{C}, 24 \mathrm{~h}$ $84 \%$ yield, $95: 5$ e.

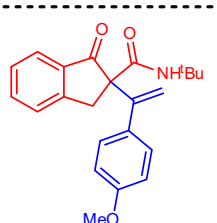

3ad, $50{ }^{\circ} \mathrm{C}, 24 \mathrm{~h}$ $99 \%$ yield, 93:7 e.r.

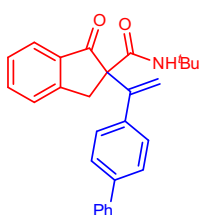

3ai, $60{ }^{\circ} \mathrm{C}, 48 \mathrm{~h}$ $77 \%$ yield, $91: 9$ e.r.

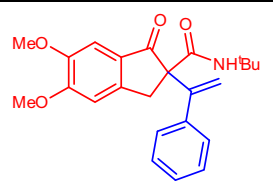

3ea, $50^{\circ} \mathrm{C}, 24 \mathrm{~h}$ $97 \%$ yield, $95.5: 4.5$ e r. $\quad 98 \%$ yield, $85: 15$ e.r.

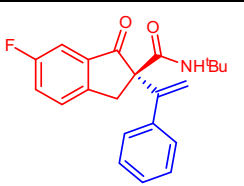

(R)-3ae, $60{ }^{\circ} \mathrm{C}, 24 \mathrm{~h}$ $97 \%$ yield, 93:7 e.r.

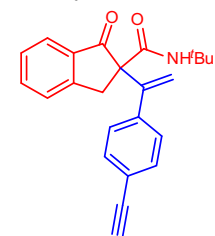

3aj, $60^{\circ} \mathrm{C}, 24 \mathrm{~h}$ $58 \%$ yield, 95.5:4.5e.r.

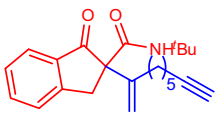

$3 \mathrm{ap}^{\mathrm{b}}, 50^{\circ} \mathrm{C}, 120 \mathrm{~h}$ $53 \%$ yield, $89.5: 10.5$ e.r.

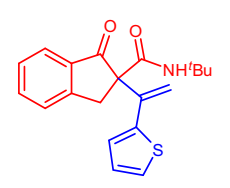

3ak, $50{ }^{\circ} \mathrm{C}, 24 \mathrm{~h}$ $99 \%$ yield, $94: 6$ e.r.

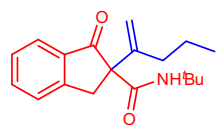

$3 \mathrm{an}^{\mathrm{b}}, 50^{\circ} \mathrm{C}, 120 \mathrm{~h}$ $54 \%$ yield, $90: 10$ e.r.

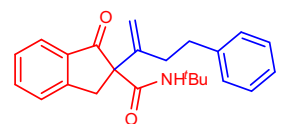

$3 \mathrm{ao}^{\mathrm{b}}, 50^{\circ} \mathrm{C}, 120 \mathrm{~h}$ $95 \%$ yield, $91.5: 8.5$ e.r.

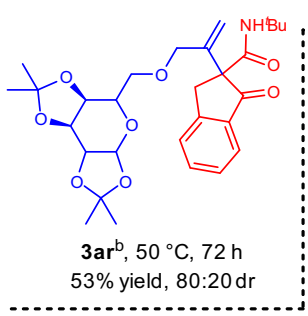

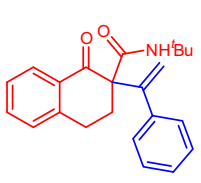

3ha, $70^{\circ} \mathrm{C}, 96 \mathrm{~h}$ 95\% yield, $91: 9$ e.r.

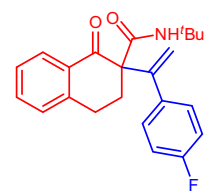

3he, $60^{\circ} \mathrm{C}, 120 \mathrm{~h}$ $65 \%$ yield, $94: 6$ e.r.

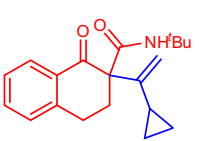

$3 \mathrm{hm}, 60^{\circ} \mathrm{C}, 120 \mathrm{~h}$ $32 \%$ yield, 93.5:6.5 e.r.

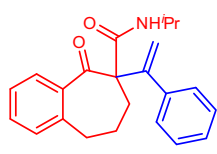

3 ia, $70^{\circ} \mathrm{C}, 96 \mathrm{~h}$ $27 \%$ yield, $69: 31$ e.r.

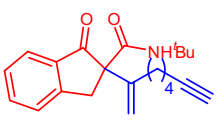

$3 \mathrm{aq}^{\mathrm{c}}, 50^{\circ} \mathrm{C}, 120 \mathrm{~h}$ $38 \%$ yield, $86.5: 13.5$ e.r.

Fig. 2 Substrate scope of the reaction about $\boldsymbol{\beta}$-ketoamides. Unless otherwise noted, all reactions were carried out, AuCl•PPh $/$ AgOTf (1:1, 5 mol\%), In $(\mathrm{OTf})_{3} / \mathbf{L}_{-} \mathbf{P i E t}_{\mathbf{2}} \mathbf{M e}(1: 1.2,10 \mathrm{~mol} \%), \mathbf{1}(0.10 \mathrm{mmol})$ and $\mathbf{2}$ (2.0 equiv), $\mathrm{H}_{2} \mathrm{O}(2 \mu \mathrm{L})$ as additive in $p$-xylene $(1.5 \mathrm{~mL})$ at $50-70{ }^{\circ} \mathrm{C}$ for $24-120 \mathrm{~h}$. Isolated yields. The e.r. values were determined by HPLC analysis on chiral column. ${ }^{2} \mathbf{L}-\mathbf{P i E t}_{\mathbf{2}}$ was used as ligand. b3.0 equiv of $\mathbf{2}$ was used. ${ }^{\mathrm{C}} \mathbf{L}-\mathbf{P i M \mathbf { e } _ { \mathbf { 3 } }}$ was used as ligand.

was also tolerated, affording the product $\mathbf{3 j a}$ in moderate yield with good enantioselectivity. The absolute configuration of 3ae was determined to be $R$ by $\mathrm{X}$-ray crystallographic analysis and the absolute configurations of $\mathbf{3} \mathbf{a a}-\mathbf{3 a c}$ and $\mathbf{3} \mathbf{a g}-\mathbf{3} \mathbf{a h}$ were determined to be $R$ by comparison of the CD spectra with that of 3ae (Fig. 2).

Effect of $\mathrm{N}$-protecting group. Other easily removable $\mathrm{N}$-protecting groups such as $N$-benzyl or $N$-PMP were investigated by reacting with phenylacetylene (Table 2 ). The desired products $3 \mathbf{k a}$ and 3la were obtained in excellent yields but with only 56.5:43.5 e. r. and 72.5:27.5 e.r. under standard conditions. After changing the ligand to L-TQ-(S)-EPh derived from $(S)$-tetrahydroisoquinoline3-carbonyl acid and $(S)$-phenylethanamine, adjusting the reaction temperature and solvent, the enantioselectivities were improved sharply to 90:10 e.r. and 89:11 e.r., respectively. The possible reason might be that the $N$-protecting group, amide moiety and backbones of the catalyst are included in discrimination of $R e$ and $\mathrm{Si}$-face of the 1,3-dicarbonyl compounds. With $\mathbf{L}$-PiEt $\mathbf{P}_{\mathbf{2}} \mathbf{M e}$ as ligand, the bulky $N$-tertbutylamide moiety could help to shield the Si-face of substrate 1a efficiently. On the contrary, the $N$ benzyl or PMP with smaller steric hindrance showed poor ability to shield the Si-face of the 1,3-dicarbonyl compounds, causing the e.r. values of the products decreased sharply in the $\mathbf{L}-\mathbf{P i E t}_{2} \mathbf{M e} / \mathrm{In}$ (III) system. Changing to the L-TQ-(S)-EPh/In(III) system, the steric hindrance of amide moiety and backbones of the catalyst increased, and the $\mathrm{Si}$-face of the 1,3-dicarbonyl compounds could also shield better; therefore, the e.r. values of products increased.

Substrate scope of the reaction about $\beta$-ketoesters. When $\beta$-ketoesters $\mathbf{4 a}$ was applied in the $\operatorname{In}(\mathrm{OTf})_{3} / \mathbf{L}$-PiEt $\mathbf{H}_{\mathbf{2}} \mathbf{M e}$ catalytic 


\section{Table 2 Effect of $\mathbf{N}$-protecting group.}

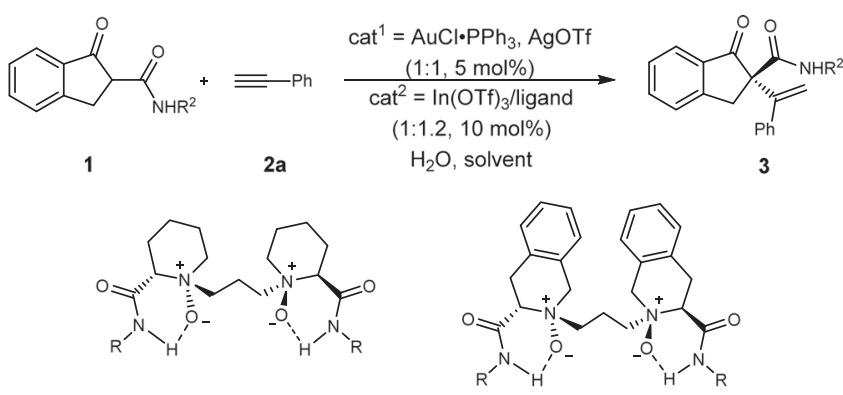

L-PiEt 2 Me: $\mathrm{R}=2,6-\mathrm{Et}_{2}-4-\mathrm{MeC}_{6} \mathrm{H}_{2} \quad$ L-TQ-(S)-EPh: $\mathrm{R}=(\mathrm{s})-2-$ phenylethyl

\begin{tabular}{|c|c|c|c|c|}
\hline Entry & $R^{2}$ & Ligand & Yielda (\%) & e.r.b \\
\hline 1 & $\mathrm{Bn}$ & L-PiEt ${ }_{2} \mathbf{M e}$ & 99 & $56.5: 43.5$ \\
\hline $2^{c}$ & (3ka) & L-TQ-(S)-EPh & 99 & $90: 10$ \\
\hline 3 & PMP & L-PiEt $_{2} \mathbf{M e}$ & 96 & $72.5: 27.5$ \\
\hline $4^{d}$ & $31 a$ & L-TQ-(S)-EPh & 98 & $89: 11$ \\
\hline
\end{tabular}

Unless otherwise noted, all reactions were carried out, $\mathrm{AuCl} \cdot \mathrm{PPh}_{3} / \mathrm{AgOTf}(1: 1,5 \mathrm{~mol} \%), \ln (\mathrm{OTf})_{3} /$ ligand $(1: 1.2,10 \mathrm{~mol} \%), \mathbf{1}(0.10 \mathrm{mmol})$ and $\mathbf{2 a}(2.0 \mathrm{equiv})$ in para-xylene $(1.5 \mathrm{~mL})$ at $50{ }^{\circ} \mathrm{C}$ for $24 \mathrm{~h}$. Bn benzyl group, PMP p-methoxyphenyl group.

aYield of isolated product 3.

betermined by chiral HPLC analysis.

cReact at $35^{\circ} \mathrm{C}$ for $72 \mathrm{~h}$

dReact at $60^{\circ} \mathrm{C}$ in toluene $(1.5 \mathrm{~mL})$ for $48 \mathrm{~h}$.

system, the desired product was obtained in only $10 \%$ yield with 58.5:41.5 e.r.. After extensive investigation, including use of $\mathrm{Ni}$ $(\mathrm{OTf})_{2} / \mathbf{L}-\mathbf{P i M e}_{2}$ as catalyst and prolonging the reaction time, the corresponding product 5 aa could be obtained in $47 \%$ yield with 97.5:2.5 e.r.. The decomposition of substrate $\mathbf{4 a}$ is responsible for the moderate yield. More stable $\mathbf{4 b}$ with a smaller steric hindrance of ester protecting group could transform to the desired $\mathbf{5 b a}$ in 72\% yield with 93.5:6.5 e.r.. Different ketoesters 4 derived from 1indanones bearing electron-donating group or withdrawing group tolerated well. Moreover, both aliphtic alkynes and aromatic alkynes were suitable in the reaction. The yields were generally good except product $\mathbf{5 b c}$. The possible reason might be that the electron-withdrawing effect of the fluorine weakened the interaction between gold catalyst and alkyne (Fig. 3).

Substrate scope of the reaction about 1,3-diketones. 1,3-Diketones were next investigated. With $\mathrm{Ni}(\mathrm{OTf})_{2} / \mathbf{L}-\mathbf{P i E t}_{2} \mathbf{M e}$ as catalyst, a variety of 1,3-diketons with no matter electron-donating group or electron-withdrawing group on the C5-position or C6position transformed to the corresponding products $7 \mathbf{a a}-7 \mathrm{ga}$ in 74-96\% yields with 91:9-96.5:3.5 e.r.. Besides, aromatic, aliphatic, and hetero-aromatic 1-alkynes 2 were suitable substrates (Fig. 3).

Substrate scope limitation. For acyclic $\beta$-ketoamide 8a, which without other substituent on $\alpha$-position, transformed to thermodynamically stable achiral $\alpha, \beta$-conjugated carbonyl product 9aa through olefin isomerization (Fig. 4). When acyclic $\beta$ ketoamides $\mathbf{8 b}-\mathbf{8 i}$ bearing methyl, phenyl, benzyl, or chlorine group on the $\alpha$-position were used as the nucleophiles, the corresponding products could not be observed. The possible reason might be that the a-substitution on the 1,3-dicarbonyl compounds increased the steric hindrance when the two activated substrates participate in the reaction.

Substrate scope of $\boldsymbol{\alpha}$-fluoro substituted acyclic $\boldsymbol{\beta}$-ketoamides. Therefore, $\boldsymbol{\alpha}$-fluoro substituted $\mathbf{8 j}$ with smaller steric hindrance and stronger acidity of $\alpha$-proton was evaluated (Fig. 5). Moderate yields with good e.r. could be obtained after adjusting the ligand to $\mathbf{L}-\mathbf{P i E t}_{\mathbf{2}}$, increasing the reaction temperature and prolonging the reaction time. Electron-donating or electron-withdrawing substitutes on the para-position of phenyl ring were tolerated well. Generally, the 1-alkynes 2 with an electron-donating substituent led to better yields than the ones with electronwithdrawing substituents. Compared with the phenylacetylene, the more electron-rich aromatic alkynes like $2 \mathbf{l}$ and $2 \mathrm{~s}$ showed better reactivities (9jl and $\mathbf{9 j s})$. When aliphatic 1-alkynes $\mathbf{2} \mathbf{m}$ and 2n were applied to the reaction, the products were delivered in moderate yields with good e.r. values.

Mechanism investigation. Next, the reaction mechanism was investigated (Fig. 6). Some control experiments were carried out (Fig. 6a). In the absence of AuCl.PPh $3 / \mathrm{AgOTf}$ or $\operatorname{In}(\mathrm{OTf})_{3} / \mathrm{L}$ $\mathbf{P i E t}_{2} \mathbf{M e}$, only trace amount of the product $\mathbf{3 a a}$ was detected, which indicates that the two catalysts work cooperatively. $N, N^{\prime}$ dioxide/ $\mathrm{In}(\mathrm{OTf})_{3}$ crystal structure obtained in our previous study ${ }^{49}$ showed that a $\mathrm{OH}$-bridged dinuclear indium complex forms in the presence of $\mathrm{H}_{2} \mathrm{O}$, in which $N, N^{\prime}$-dioxide coordinates to In(III) in a tetradentate manner. Nevertheless, the investigation of relationship between the e.e. value of $\mathbf{L}-\mathbf{P i E t}_{2} \mathbf{M e}$ and that of 3aa showed a clear linear effect (Fig. 6b), implying that the active catalytic species is likely to be the mixture of $\operatorname{In}(\mathrm{OTf})_{3}$ and $\mathbf{L}_{-} \mathbf{P i E t}_{\mathbf{2}} \mathbf{M e}$ in a 1:1 ratio. The $\mathrm{OH}$ anion generated from the water in situ preparation of the chiral indium catalyst might act as a base to accelerate the enolization of 1,3-dicarbonyl compounds. In addition, the $\mathrm{M}^{+}$peak (found: 561.1058), which corresponded to a $1: 1$ complex $\mathbf{C}$ of $\left[\mathrm{Au} \cdot \mathrm{PPh}_{3}\right]^{+}$and phenylacetylene $2 \mathbf{a}$, was detected by ESI-TOF analysis in the positive-ion mode. The mixture of $\mathbf{L}-\mathbf{P i E t}_{2} \mathbf{M e}, \operatorname{In}(\mathrm{OTf})_{3}$, and 1a (1:1:1) in p-xylene displaying an ion at $\mathrm{m} / \mathrm{z} 1114.4025\left(\left[\mathbf{L}^{-} \mathbf{P i E t}{ }_{2} \mathbf{M e}+\mathrm{In}^{3+}+\mathrm{OTf}^{-}+\mathbf{1 a}-\right.\right.$ $\left.\mathrm{H}^{+}\right] \mathrm{m} / \mathrm{z}$ calcd 1114.4036$)$ suggested that enolized 1a coordinates to the catalyst in a $1: 1$ molecular ratio (Fig. 6c), which is consistent with our non-linear effect.

Proposed catalytic cycle and transition-state model. Based on the above analysis and previous work, a catalytic cycle with a 


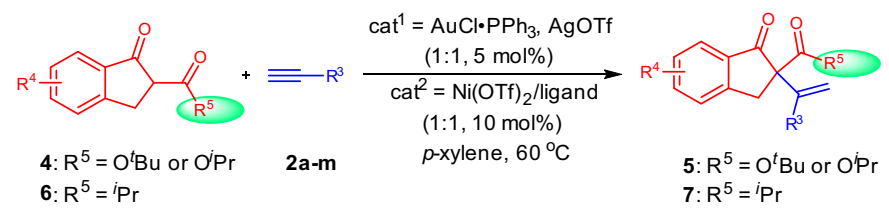

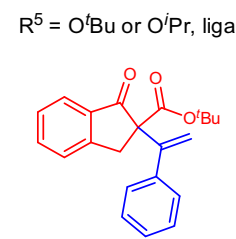

$5 a^{\mathrm{a}}, 50^{\circ} \mathrm{C}, 48 \mathrm{~h}$ $10 \%$ yield, 58.5:41.5e.r.

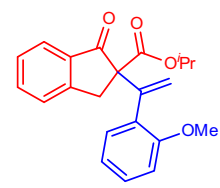

5bf, $60^{\circ} \mathrm{C}, 72 \mathrm{~h}$ $90 \%$ yield, $94: 6$ e.r.

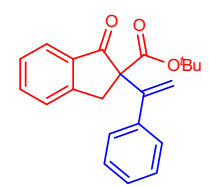

$5 a^{\mathrm{b}}, 50^{\circ} \mathrm{C}, 48 \mathrm{~h}$

$47 \%$ yield, $97.5: 2.5$ e.r.

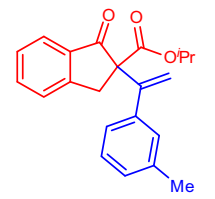

$5 \mathrm{bh}, 60^{\circ} \mathrm{C}, 72 \mathrm{~h}$ $71 \%$ yield, $91.5: 8.5$ e.r.

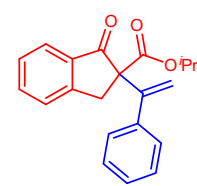

5ba, $60^{\circ} \mathrm{C}, 72 \mathrm{~h}$

$72 \%$ yield, $93.5: 6.5$ e.r.

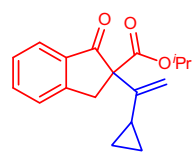

$5 \mathrm{bm}, 60^{\circ} \mathrm{C}, 72 \mathrm{~h}$

$82 \%$ yield, $95: 5$ e.r.

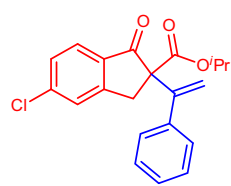

$5 \mathrm{ca}, 60^{\circ} \mathrm{C}, 72 \mathrm{~h}$ $89 \%$ yield, $91.5: 8.5$ e.r.

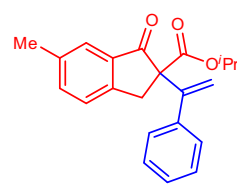

$5 \mathrm{da}, 60^{\circ} \mathrm{C}, 72 \mathrm{~h}$ $89 \%$ yield, $91: 9$ e.r.

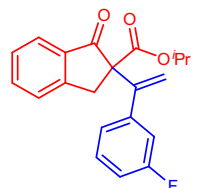

5bc, $60^{\circ} \mathrm{C}, 72 \mathrm{~h}$ $40 \%$ yield, $87: 13$ e.r.

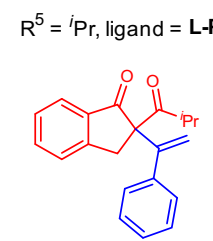

$7 \mathrm{aa}, 60^{\circ} \mathrm{C}, 48 \mathrm{~h}$ $96 \%$ yield, $95: 5$ e.r.

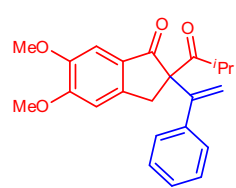

7 ga $, 60^{\circ} \mathrm{C}, 72 \mathrm{~h}$ $74 \%$ yield, $95: 5$ e.r.

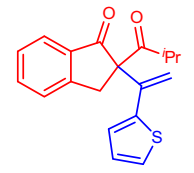

7 ak, $60^{\circ} \mathrm{C}, 72 \mathrm{~h}$ 99\% yield, 96.5:3.5e.r.

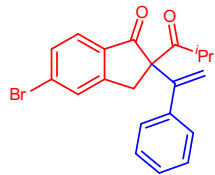

7 ba, $60^{\circ} \mathrm{C}, 72 \mathrm{~h}$

$95 \%$ yield, $91: 9$ er.

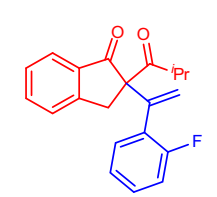

$7 \mathrm{ab}, 60^{\circ} \mathrm{C}, 72 \mathrm{~h}$ $84 \%$ yield, $93: 7$ e.r.

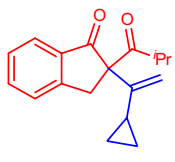

7 am, $60{ }^{\circ} \mathrm{C}, 72 \mathrm{~h}$

$84 \%$ yield, $96.5: 3.5$ e.r.
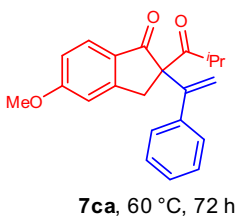

$7 \mathrm{ca}, 60 \mathrm{C}, 72 \mathrm{~h}$

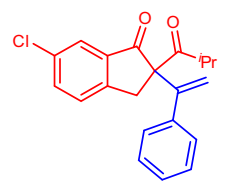

7 da, $60^{\circ} \mathrm{C}, 72 \mathrm{~h}$

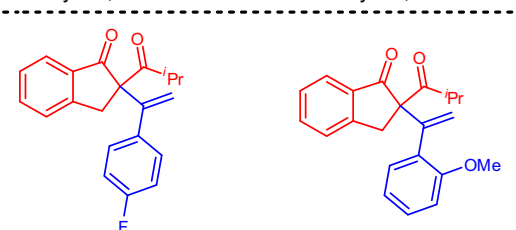

7 ae, $60{ }^{\circ} \mathrm{C}, 72 \mathrm{~h}$ $73 \%$ yield, $96: 4$ e.r.

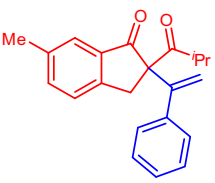

7ea, $60^{\circ} \mathrm{C}, 72 \mathrm{~h}$ $76 \%$ yield, 96.5 .35<smiles>C=C(c1ccc(Cl)cc1)C1(C(=O)P)Cc2ccccc2C1=O</smiles>

7 ag, $60^{\circ} \mathrm{C}, 72 \mathrm{~h}$ $62 \%$ yield, $87.5: 12.5$ e.r.

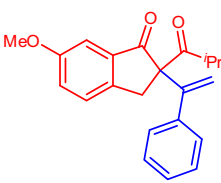

$7 \mathrm{fa}, 60^{\circ} \mathrm{C}, 72 \mathrm{~h}$ $87 \%$ yield, 96.5 .5 er.

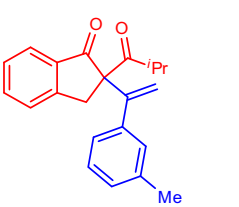

7 ah $60{ }^{\circ} \mathrm{C}, 72 \mathrm{~h}$ $99 \%$ yield, $94.5: 5.5$ e.r.

Fig. 3 Substrate scope of the reaction about $\boldsymbol{\beta}$-ketoesters and 1,3-diketones. Unless otherwise noted, all reactions were carried out, $\mathrm{AuCl} \bullet \mathrm{PPh} / \mathrm{AgOTf}$ $(1: 1,5 \mathrm{~mol} \%), \mathrm{Ni}(\mathrm{OTf})_{2} /$ ligand $(1: 1,10 \mathrm{~mol} \%), 4$ or $\mathbf{6}(0.10 \mathrm{mmol})$ and $\mathbf{2}\left(2.0\right.$ equiv) in $p$-xylene $(1.0 \mathrm{~mL})$ at $60^{\circ} \mathrm{C}$ for $48-72 \mathrm{~h}$. Isolated yields. The e.r. values were determined by HPLC analysis on chiral column. ${ }^{a} \mathrm{n}(\mathrm{OTf})_{3} / \mathbf{L}-\mathbf{P i E t}_{\mathbf{2}} \mathbf{M e}=1: 1.2,10 \mathrm{~mol} \%, \mathrm{p}$-xylene $(1.5 \mathrm{~mL}), 24 \mathrm{~h}$. ${ }^{\mathrm{b}} \mathbf{L}-\mathbf{P i M e} \mathbf{2}$ was used as ligand.

possible transition state is proposed. As illustrated in Fig. 7, in $\mathbf{L}-\mathbf{P i E t}_{2} \mathbf{M e} / \operatorname{In}(\mathrm{OTf})_{3}$ cycle, initially, the tetradentate L-PiEt $_{2} \mathbf{M e}$ coordinates to In ${ }^{\text {III }}$ to form a six-coordinate octahedral geometry complex $\mathbf{A}^{\prime}$ and dimer A. When ketoamide 1a was added, the basic anion of the catalytic species accelerates the deprotonation process, and the enol ion of $\mathbf{1 a}$ coordinates tightly to chiral indium(III) center through two oxygens to form the carbanion nucleophile intermediate $\mathbf{B}$. On the other hand, as for $[\mathrm{Au}]$ cycle, the [Au]OTf, which is the more reactive species, would bind to the $\pi$-bond of 1 -alkyne 2 in an unsymmetrical fashion to form species $\mathbf{C}$. The intermediate $\mathbf{C}$ then reacts with the complex $\mathbf{B}$ to form the $\mathrm{Au} / \mathrm{In}$ stabilized reactive intermediate $\mathbf{T S}$, which is the origin of the stereoselectivity. Due to the Si-face of $\beta$-ketoamides, 1 a is effectively shielded by the amide moiety of the catalyst, with the assistance of $N$-protecting group on $\beta$-ketoamide and piperidine ring on the ligand, cat $^{1}$-activated $\pi$-bond of $\mathbf{2 a}$ approaches preferably from the $R e$-face to undergo an energetically favorable $\mathrm{C}-\mathrm{C}$ bond forming reaction, forming the complex $\mathbf{D}$ with $R$ absolute configuration at the newly formed stereogenic 
center. Subsequent protonation of $\mathbf{D}$ gives the desired product 3 and releases the two catalysts.

\section{Discussion}

An efficient catalytic asymmetric Nakamura reaction of $\beta$ ketoamides, $\beta$-ketoesters, and 1,3-diketones with unactivated 1 -
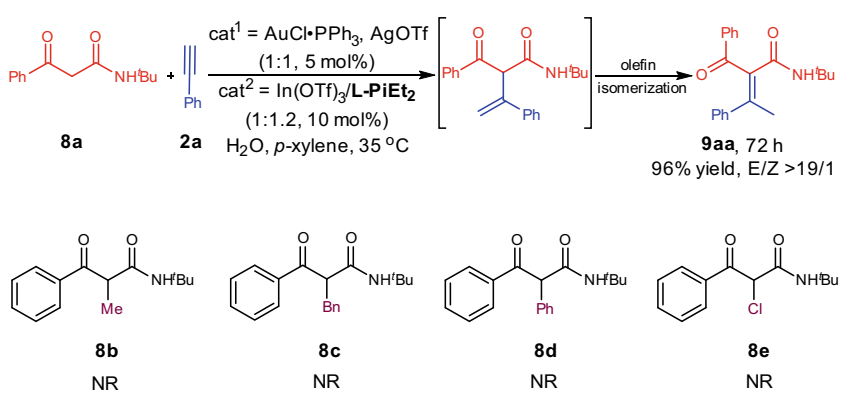

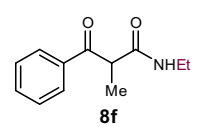

NR

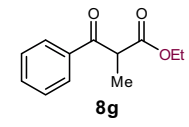

NR<smiles>CC(C(=O)O)C(=O)C1=CC=CC1</smiles>

8h

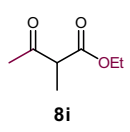

NR
Fig. 4 Substrate scope limitation of $\boldsymbol{\alpha}$-substituted acyclic $\boldsymbol{\beta}$-ketoamides. Unless otherwise noted, all reactions were carried out, $\mathrm{AuCl}_{\bullet} \mathrm{PPh}_{3} / \mathrm{AgOTf}$ (1:1, 5 mol\%), In(OTf) $/ \mathbf{L}^{-P_{i E t}} \mathbf{2}(1: 1.2,10 \mathrm{~mol} \%), 8(0.10 \mathrm{mmol})$ and $\mathbf{2 a}(3.0$ equiv), $\mathrm{H}_{2} \mathrm{O}(2 \mu \mathrm{L})$ as additive in $p$-xylene $(1.5 \mathrm{~mL})$ at $70^{\circ} \mathrm{C}$ for $120 \mathrm{~h}$. alkynes is realized by developing a bimetallic synergistic catalysis. The combination of $\pi$-acid gold(I)/chiral $N, N^{\prime}$-doxide-indium (III) or nickel(II) complex enables the activation of alkyne and the efficiency and stereoselectivity of nucleophile. The steric hindrance of a-substituent on 1,3-dicarbonyl compounds and hard Lewis acid are found crucial factors for the reactivity of the reaction. In addition, the substituent of 1,3-dicarbonyl compounds, the amide moiety, and backbones of the catalyst are found to affect the enantioselectivity of the reaction greatly. A possible catalytic cycle with a transition-state model was proposed to elucidate the process of the reaction and origin of chiral induction. Further studies on hetero bimetallic synergistic or relay catalysis are underway in our laboratory.

\section{Methods}

Typical procedure for cyclic $\beta$-ketoamides involved in catalytic asymmetric reaction. A mixture of $\mathrm{AuCl} \cdot \mathrm{PPh}_{3}(5 \mathrm{~mol} \%, 2.5 \mathrm{mg})$, AgOTf (5 mol\%, $\left.1.3 \mathrm{mg}\right)$, In $\left(\mathrm{OTf}_{3}(10 \mathrm{~mol} \%, 5.6 \mathrm{mg}), \mathbf{L}_{-} \mathbf{P i E t}_{2} \mathbf{M e}(12 \mathrm{~mol} \%, 7.4 \mathrm{mg})\right.$, and the $N$-(tert-butyl) -1-oxo-2,3-dihydro- $1 \mathrm{H}$-indene-2-carboxamide $\mathbf{1 a}(0.10 \mathrm{mmol})$ was added to a test tube under $\mathrm{N}_{2}$ atmosphere. Then, anhydrous para-xylene $(1.5 \mathrm{~mL})$ was added and the mixture was stirred at $30^{\circ} \mathrm{C}$ for $30 \mathrm{~min}$. Subsequently, $\mathrm{H}_{2} \mathrm{O}(1.1$ equiv, $2.0 \mu \mathrm{L}$ ) was added under stirring at $30^{\circ} \mathrm{C}$. Five minutes later, phenylacetylene 2a

(2.0 equiv, $22 \mu \mathrm{L}$ ) was added at $50^{\circ} \mathrm{C}$, and the reaction mixture continued stirring at $50{ }^{\circ} \mathrm{C}$ for $24 \mathrm{~h}$. The residue was purified by flash chromatography on silica gel (petroleum ether/ethyl acetate $=15: 1, \mathrm{v} / \mathrm{v})$ to afford the desired product 3aa $(98 \%$ yield, 94.5:5.5 e.r.).

Typical procedure for $\boldsymbol{\beta}$-ketoesters involved in catalytic asymmetric reaction. A mixture of AuCl.PPh 3 (5 mol\%, $2.5 \mathrm{mg})$, AgOTf ( $5 \mathrm{~mol} \%, 1.3 \mathrm{mg}), \mathrm{Ni}(\mathrm{OTf})_{2}$ (10 $\mathrm{mol} \%, 3.6 \mathrm{mg}), \mathrm{L}_{-} \mathrm{PiMe}_{3}(10 \mathrm{~mol} \%, 5.6 \mathrm{mg}$ ), and the isopropyl 1-oxo-2,3-

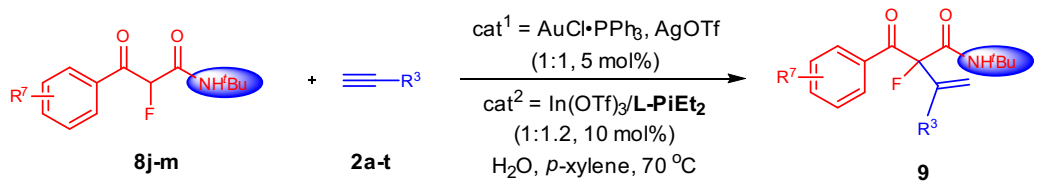

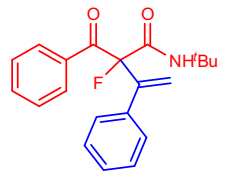

$9 \mathrm{ja}, 70^{\circ} \mathrm{C}, 120 \mathrm{~h}$ $46 \%$ yield, $91.5: 8.5$ e.r.

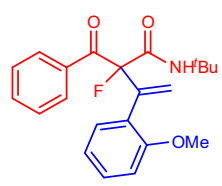

$9 j \mathrm{jf}, 70^{\circ} \mathrm{C}, 120 \mathrm{~h}$ $80 \%$ yield, $92.5: 7.5$ e.r.

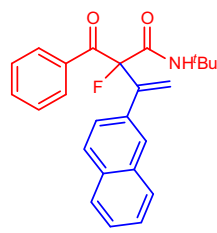

$9 j s, 70^{\circ} \mathrm{C}, 120 \mathrm{~h}$ $81 \%$ yield, $91: 9$ e.r.

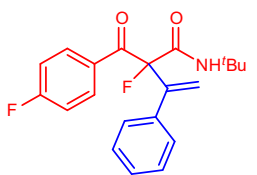

9ka, $70^{\circ} \mathrm{C}, 120 \mathrm{~h}$ $54 \%$ yield, $89: 11$ e.r.

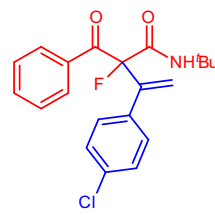

9jg, $70^{\circ} \mathrm{C}, 120 \mathrm{~h}$ $33 \%$ yield, $90: 10$ e.r.

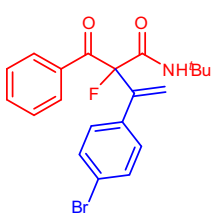

$9 j \mathrm{jt}, 70^{\circ} \mathrm{C}, 120 \mathrm{~h}$ $35 \%$ yield, $87: 13$ e.r.

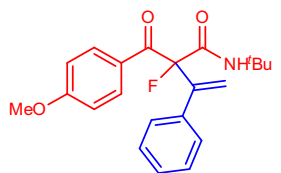

9la, $70^{\circ} \mathrm{C}, 120 \mathrm{~h}$ $62 \%$ yield, $93: 7$ e.r.

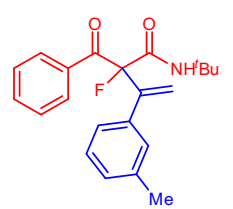

9jh, $70^{\circ} \mathrm{C}, 120 \mathrm{~h}$ $68 \%$ yield, $88: 12$ e.r.

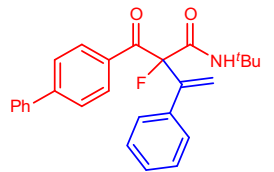

$9 \mathrm{ma}, 70^{\circ} \mathrm{C}, 120 \mathrm{~h}$ $43 \%$ yield, $89: 11$ e.r.

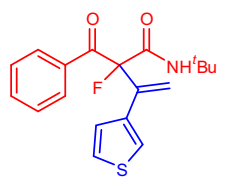

$9 \mathrm{jl}, 70^{\circ} \mathrm{C}, 120 \mathrm{~h}$ $74 \%$ yield, $92: 8$ e.r.

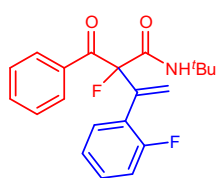

9jb, $70^{\circ} \mathrm{C}, 120 \mathrm{~h}$ $40 \%$ yield, $91: 9$ e.r.<smiles>C=C(NC(=O)C1CC1)C(F)(C(=O)c1ccccc1)C(=O)c1ccccc1</smiles>

$9 j \mathrm{~m}, 70^{\circ} \mathrm{C}, 120 \mathrm{~h}$ $60 \%$ yield, $90: 10$ e.r.

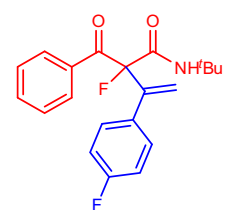

$9 \mathrm{je}, 70^{\circ} \mathrm{C}, 120 \mathrm{~h}$ $48 \%$ yield, $92: 8$ e.r.

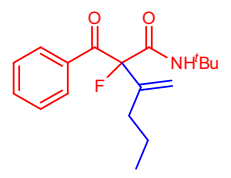

$9 \mathrm{jn}, 70^{\circ} \mathrm{C}, 120 \mathrm{~h}$ $33 \%$ yield, $87: 13$ e.r.

Fig. 5 Substrate scope of $\boldsymbol{\alpha}$-fluoro substituted acyclic $\boldsymbol{\beta}$-ketoamides. Unless otherwise noted, all reactions were carried out, $\mathrm{AuCl} \bullet \mathrm{PPh}_{3} / \mathrm{AgOTf}(1: 1,5 \mathrm{~mol}$ $\%), \ln (\mathrm{OTf})_{3} / \mathbf{L}^{-P_{i E t}} \mathbf{2}(1: 1.2,10 \mathrm{~mol} \%), 8(0.10 \mathrm{mmol})$ and $\mathbf{2}\left(3.0\right.$ equiv), $\mathrm{H}_{2} \mathrm{O}(2 \mu \mathrm{L})$ as additive in $p$-xylene $(1.5 \mathrm{~mL})$ at $70{ }^{\circ} \mathrm{C}$ for $120 \mathrm{~h}$. 


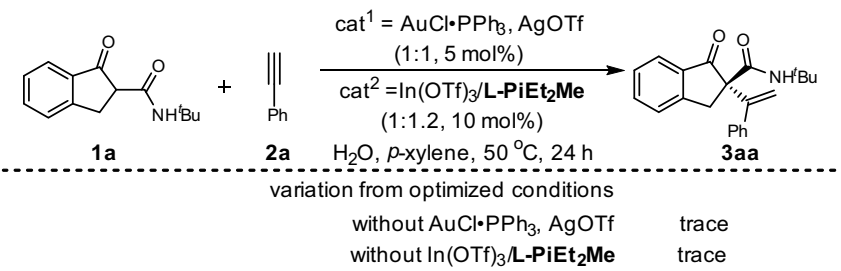

b
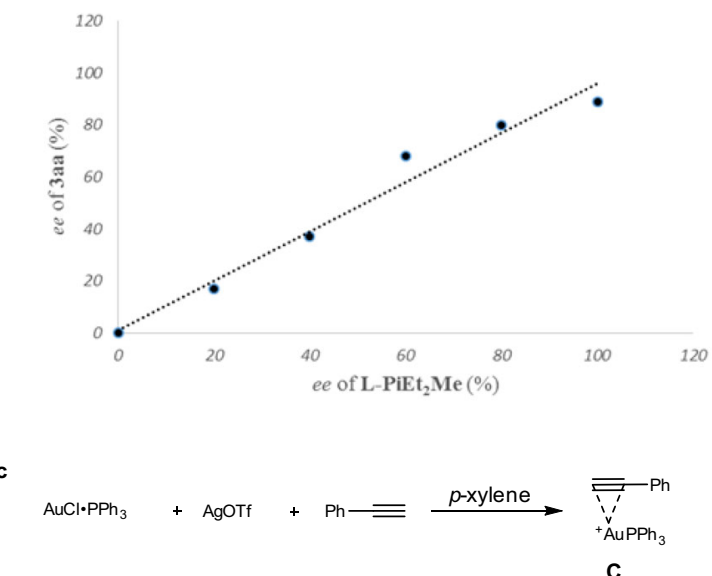

calcd for: 561.1041 found: 561.1058

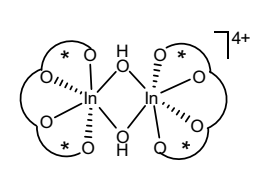

A

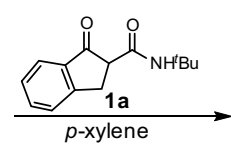

p-xylene

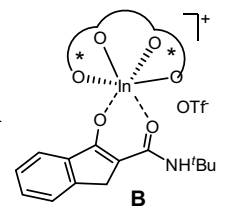

calcd for: 1114.4036 found 1114.4025
Fig. 6 Mechanism investigation. a Control experiments for reaction conditions. $\mathbf{b}$ The relationship between the ee value of $\mathbf{L}-\mathbf{P i E t}_{\mathbf{2}} \mathbf{M e}$ and $\mathbf{3} \mathbf{a a}$. c The ESI-TOF analysis of intermediate $\mathbf{B}$ and $\mathbf{C}$.

dihydro- $1 H$-indene-2-carboxylate $\mathbf{4 b}(0.10 \mathrm{mmol})$ was added to a test tube under $\mathrm{N}_{2}$ atmosphere. Then, anhydrous para-xylene $(1.0 \mathrm{~mL})$ was added and the mixture was stirred at $30^{\circ} \mathrm{C}$ for $30 \mathrm{~min}$. Subsequently, phenylacetylene 2a $(2.0$ equiv, $22 \mu \mathrm{L}$ ) was added at $60^{\circ} \mathrm{C}$, and the reaction mixture continued stirring at $60{ }^{\circ} \mathrm{C}$ for $72 \mathrm{~h}$. The residue was purified by flash chromatography on silica gel (petroleum ether/ethyl acetate $=20: 1, \mathrm{v} / \mathrm{v})$ to afford the desired product $5 \mathbf{b a}(72 \%$ yield, 93.5:6.5 e.r.).

Typical procedure for 1,3-diketones involved in catalytic asymmetric reaction. A mixture of AuCl. $\mathrm{PPh}_{3}$ (5 mol\%, $2.5 \mathrm{mg}$ ), AgOTf ( $5 \mathrm{~mol} \%, 1.3 \mathrm{mg}$ ), Ni(OTf) (10 mol\%, $3.6 \mathrm{mg}), \mathrm{L}-\mathrm{PiEt}_{2} \mathrm{Me}(10 \mathrm{~mol} \%, 6.2 \mathrm{mg})$, and the 2 -isobutyryl-2,3-dihydro- $1 \mathrm{H}$-inden-1-one $\mathbf{6 a}(0.10 \mathrm{mmol})$ was added to a test tube under $\mathrm{N}_{2}$ atmosphere. Then, anhydrous para-xylene $(1.0 \mathrm{~mL})$ was added and the mixture was stirred at $30^{\circ} \mathrm{C}$ for $30 \mathrm{~min}$. Subsequently, phenylacetylene $2 \mathrm{a}(2.0$ equiv, $22 \mu \mathrm{L})$ was added at $60^{\circ} \mathrm{C}$, and the reaction mixture continued stirring at $60^{\circ} \mathrm{C}$ for $48 \mathrm{~h}$. The residue was purified by flash chromatography on silica gel (petroleum ether/ ethyl acetate $=25: 1, \mathrm{v} / \mathrm{v}$ ) to afford the desired product $7 \mathbf{a a}$ ( $96 \%$ yield, $95: 5$ e.r.).

Typical procedure for acyclic $\beta$-ketoamides involved in catalytic asymmetric reaction. A mixture of $\mathrm{AuCl}^{-\mathrm{PPh}_{3}}(5 \mathrm{~mol} \%, 2.5 \mathrm{mg})$, AgOTf (5 mol\%, $\left.1.3 \mathrm{mg}\right)$, In $(\mathrm{OTf})_{3}(10 \mathrm{~mol} \%, 5.6 \mathrm{mg}), \mathrm{L}_{-} \mathbf{P i E t}_{2}(12 \mathrm{~mol} \%, 7.1 \mathrm{mg})$, and the $\mathrm{N}$-(tert-butyl)-2fluoro-3-oxo-3-phenylpropanamide $8 \mathbf{j}(0.10 \mathrm{mmol})$ was added to a test tube under $\mathrm{N}_{2}$ atmosphere. Then, anhydrous para-xylene $(1.5 \mathrm{~mL})$ was added and the mixture was stirred at $30^{\circ} \mathrm{C}$ for $30 \mathrm{~min}$. Subsequently, $\mathrm{H}_{2} \mathrm{O}(1.1$ equiv, $2.0 \mu \mathrm{L})$ was added under stirring at $30^{\circ} \mathrm{C}$. Five minutes later, phenylacetylene 2a (3.0 equiv, $33 \mu \mathrm{L}$ ) was added at $70^{\circ} \mathrm{C}$, and the reaction mixture continued stirring at $70^{\circ} \mathrm{C}$ for $120 \mathrm{~h}$. The residue was purified by flash chromatography on silica gel

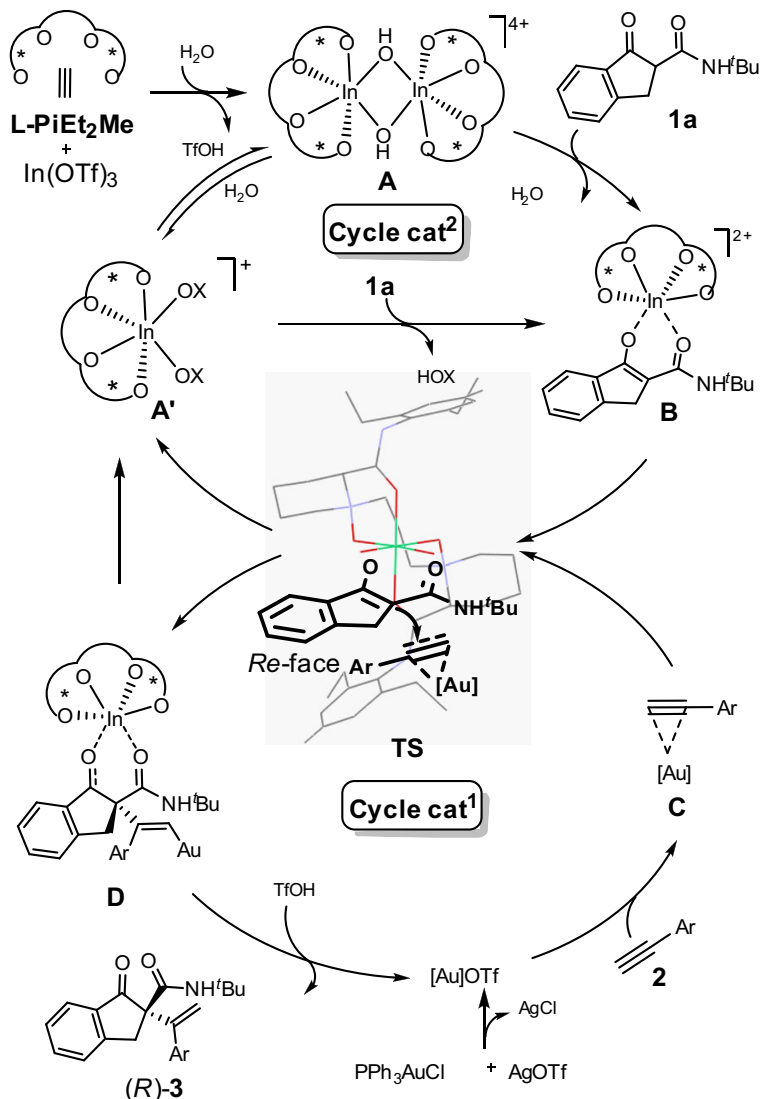

Fig. 7 Proposed catalytic cycle and transition-state model. The in situ formed chiral $N, N^{\prime}$-dioxide-indium(III) Lewis acid actives the 1,3-dicarbonyl compounds (intermediate $\mathbf{B}$ ) and achiral gold $(\mathrm{I}) \pi$-acid actives the alkyne (intermediate $\mathbf{C}$ ) synergistically; the two intermediates reacts following subsequent protonation, giving the desired product $\mathbf{3}$ and releases the two catalysts.

(petroleum ether/ethyl acetate $=6: 1, \mathrm{v} / \mathrm{v})$ to afford the desired product $9 \mathbf{9 j a}(46 \%$ yield, 91.5:8.5 e.r.).

\section{Data availability}

The X-ray crystallographic coordinate for structure 3ae reported in this study has been deposited at the Cambridge Crystallographic Data Centre (CCDC), under deposition number 1964558. The data can be obtained free of charge from The Cambridge Crystallographic Data Centre via https://www.ccdc.cam.ac.uk/structures/. All other data are available from the corresponding author upon reasonable request.

Received: 31 March 2020; Accepted: 19 March 2021; Published online: 21 May 2021

\section{References}

1. Dénès, F., Pérez-Luna, A. \& Chemla, F. Addition of metal enolate derivatives to unactivated carbon-carbon multiple bonds. Chem. Rev. 110, 2366-2447 (2010).

2. Tsuji, H. et al. Indium-catalyzed cycloisomerization of $\omega$-alkynyl- $\beta$-ketoesters into six- to fifteen-membered rings. Angew. Chem. Int. Ed. 46, 8060-8062 (2007).

3. Itoh, Y. et al. Efficient formation of ring structures utilizing multisite activation by indium catalysis. J. Am. Chem. Soc. 130, 17161-17167 (2008).

4. Zhu, S. F., Zhang, Q. H., Chen, K. \& Jiang, H. F. Synergistic catalysis: metal/ proton-catalyzed cyclization of alkynones toward bicyclo[3.n.1]alkanones. Angew. Chem. Int. Ed. 54, 9414-9418 (2015).

5. $\mathrm{Xu}, \mathrm{Y}$. et al. Organocatalytic enantioselective Conia-ene-type carbocyclization of ynamide cyclohexanones: regiodivergent synthesis of morphans and normorphans. Angew. Chem. Int. Ed. 58, 16252-16259 (2019). 
6. Kennedy-Smith, J. J., Staben, S. T. \& Toste, F. D. Gold(I)-catalyzed Conia-ene reaction of $\beta$-ketoesters with alkynes. J. Am. Chem. Soc. 126, 4526-4527 (2004).

7. Staben, S. T., Kennedy-Smith, J. J. \& Toste, F. D. Gold(I)-catalyzed 5-endo-dig carbocyclization of acetylenic dicarbonyl compounds. Angew. Chem. Int. Ed. 43, 5350-5352 (2004).

8. Clarke, M. L. \& France, M. B. The carbonyl ene reaction. Tetrahedron 64, 9003-9031 (2008).

9. Gao, Q., Zheng, B.-F., Li, J.-H. \& Yang, D. Ni(II)-catalyzed Conia-ene reaction of 1,3-dicarbonyl compounds with alkynes. Org. Lett. 7, 2185-2188 (2005).

10. Deng, C.-L., Song, R.-J., Guo, S.-M., Wang, Z.-Q. \& Li, J.-H. Copper/silvercocatalyzed Conia-ene reaction of linear $\beta$-alkynic $\beta$-ketoesters. Org. Lett. 9 5111-5114 (2007).

11. Hack, D., Blümel, M., Chauhan, P., Philipps, A. R. \& Enders, D. Catalytic Conia-ene and related reactions. Chem. Soc. Rev. 44, 6059-6093 (2015).

12. Corkey, B. K. \& Toste, F. D. Catalytic enantioselective Conia-ene reaction. J. Am. Chem. Soc. 127, 17168-17169 (2005).

13. Matsuzawa, A., Mashiko, T., Kumagai, N. \& Shibasaki, M. La/Ag heterobimetallic cooperative catalysis: a catalytic asymmetric Conia-ene reaction. Angew. Chem. Int. Ed. 50, 7616-7619 (2011).

14. Suzuki, S. et al. Enantioselective 5-endo-dig carbocyclization of $\beta$-ketoesters with internal alkynes employing a four-component catalyst system. Angew. Chem. Int. Ed. 51, 4131-4135 (2012).

15. Horibe, T., Sakakibara, M., Hiramatsu, R., Takeda, K. \& Ishihara, K. One-pot tandem Michael addition/enantioselective Conia-ene cyclization mediated by chiral iron(III)/silver(I) cooperative catalysis. Angew. Chem. Int. Ed. 59, 16470-16474 (2020).

16. Yang, T., Ferrali, A., Sladojevich, F., Campbell, L. \& Dixon, D. J. Brønsted base/Lewis acid cooperative catalysis in the enantioselective Conia-ene reaction. J. Am. Chem. Soc. 131, 9140-9141 (2009).

17. Shaw, S. \& White, J. D. A new iron(III)-salen catalyst for enantioselective Conia-ene carbocyclization. J. Am. Chem. Soc. 136, 13578-13581 (2014).

18. Blümel, M., Hack, D., Ronkartz, L., Vermeeren, C. \& Enders, D. Development of an enantioselective amine-silver co-catalyzed Conia-ene reaction. Chem. Commun. 53, 3956-3959 (2017).

19. Fang, G. S. et al. Asymmetric cyclizations via a sequential Michael addition/ Conia-ene reaction by combining multifunctional quaternary phosphonium salt and silver catalysis. Tetrahedron 75, 2706-2716 (2019).

20. Cao, M., Yesilcimen, A. \& Wasa, M. Enantioselective Conia-ene-type cyclizations of alkynyl ketones through cooperative action of $\mathrm{B}\left(\mathrm{C}_{6} \mathrm{~F}_{5}\right)_{3}$, $N$-alkylamine and a Zn-based catalyst. J. Am. Chem. Soc. 141, 4199-4203 (2019).

21. Asao, N. \& Yamamoto, Y. Lewis acid-catalyzed hydrometalation and carbometalation of unactivated alkynes. Bull. Chem. Soc. Jpn. 73, 1071-1087 (2000).

22. Fallis, A. G. \& Forgione, P. Metal mediated carbometallation of alkynes and alkenes containing adjacent heteroatoms. Tetrahedron 57, 5899-5913 (2001).

23. Nakamura, M., Endo, K. \& Nakamura, E. Indium-catalyzed addition of active methylene compounds to 1-alkynes. J. Am. Chem. Soc. 125, 13002-13003 (2003).

24. Nakamura, M., Endo, K. \& Nakamura, E. Indium triflate-catalyzed vinylation of $\beta$-ketoesters with acetylene gas. Org. Lett. 7, 3279-3281 (2005).

25. Endo, K., Hatakeyama, T., Nakamura, M. \& Nakamura, E. Indium-catalyzed 2-alkenylation of 1,3-dicarbonyl compounds with unactivated alkynes. J. Am. Chem. Soc. 129, 5264-5271 (2007).

26. Kaneda, K., Motokura, K., Nakagiri, N., Mizugaki, T. \& Jitsukawa, K. Recyclable indium catalysts for additions of 1,3-dicarbonyl compounds to unactivated alkynes affected by structure and acid strength of solid supports. Green Chem. 10, 1231-1234 (2008).

27. Rajesh, N. \& Prajapati, D. Indium-catalyzed, novel route to $\beta, \beta$-disubstituted indanones via tandem Nakamura addition-hydroarylation-decarboxylation sequence. Chem. Commun. 51, 3347-3350 (2015).

28. Sestelo, J. P., Sarandeses, L. A., Martínez, M. M. \& Alonso-Marañón, L. Indium(III) as $\pi$-acid catalyst for the electrophilic activation of carbon-carbon unsaturated systems. Org. Biomol. Chem. 16, 5733-5747 (2018).

29. Kuninobu, Y., Kawata, A. \& Takai, K. Efficient catalytic insertion of acetylenes into a carbon-carbon single bond of nonstrained cyclic compounds under mild conditions. J. Am. Chem. Soc. 128, 11368-11369 (2006).

30. Horino, Y. Rhenium-catalyzed C-H and C-C bond activation. Angew. Chem. Int. Ed. 46, 2144-2146 (2007).

31. Murai, M., Uemura, E. \& Takai, K. Amine-promoted anti-markovnikov addition of 1,3-dicarbonyl compounds with terminal alkynes under rhenium catalysis. ACS Catal. 8, 5454-5459 (2018).
32. Onodera, G., Kato, M., Kawano, R., Kometani, Y. \& Takeuchi, R. Highly regioand stereoselective addition of 1,3-diketones to internal alkynes catalyzed by cationic iridium complex. Org. Lett. 11, 5038-5041 (2009).

33. Patil, N. T. \& Yamamoto, Y. Formation of a quaternary carbon center through the $\mathrm{Pd}(0) / \mathrm{PhCOOH}$-catalyzed allylation of cyclic $\beta$-keto esters and 1,3diketones with alkynes. J. Org. Chem. 69, 6478-6481 (2004).

34. Verma, G. K., Rawat, M. \& Rawat, D. S. Cobalt-catalysed C-C bond formation and $[2+2+2]$ annulation of 1,3-dicarbonyls to terminal alkynes. Eur. J. Org. Chem. 2019, 4101-4104 (2019).

35. Kuninobu, Y. et al. Rhenium- and manganese-catalyzed insertion of alkynes into a carbon-carbon single bond of cyclic and acyclic 1,3-dicarbonyl compounds. Chem. Asian J. 4, 1424-1433 (2009).

36. Thorve, P. R., Guru, M. M. \& Maji, B. Manganese-catalyzed divergent markovnikov addition and $[2+2+2]$ cycloaddition of 2-carbonyl indanone with terminal alkyne. J. Org. Chem. 84, 8185-8193 (2019).

37. Murahashi, S.-I., Naota, T. \& Nakano, Y. Ruthenium-catalyzed regioselective reactions of nitriles and 1,3-dicarbonyl compounds with terminal alkynes. Synlett. 20, 3355-3359 (2009).

38. Cheung, H. W., So, C. M., Pun, K. H., Zhou, Z. Y. \& Lau, C. P. Hydro (trispyrazolyl)borato-ruthenium(II) diphosphinoamino complex-catalyzed addition of $\beta$-diketones to 1 -alkynes and anti-markovnikov addition of secondary amines to aromatic 1-alkynes. Adv. Synth. Catal. 353, 411-425 (2011).

39. Pennington-Boggio, M. K., Conley, B. L. \& Williams, T. J. A rutheniumcatalyzed coupling of alkynes with 1,3-diketones. J. Organomet. Chem. 716, 6-10 (2012).

40. Fujimoto, T., Endo, K., Tsuji, H., Nakamura, M. \& Nakamura, E. Construction of a chiral quaternary carbon center by indium-catalyzed asymmetric $\alpha$-alkenylation of $\beta$-ketoesters. J. Am. Chem. Soc. 130, 4492-4496 (2008).

41. Xi, Y. M. et al. Synergistic Au/Ga catalysis in ambient Nakamura reaction. Org. Lett. 16, 306-309 (2014).

42. Zheng, W.-F., Xu, Q.-J. \& Kang, Q. Rhodium/Lewis acid catalyzed regioselective addition of 1,3-dicarbonyl compounds to internal alkynes. Organometallics. 36, 2323-2330 (2017).

43. Bhattacharjee, R., Nijamudheen, A. \& Datta, A. Mechanistic insights into the synergistic catalysis by $\mathrm{Au}(\mathrm{I}), \mathrm{Ga}(\mathrm{III})$, and counterions in the Nakamura reaction. Org. Biomol. Chem. 13, 7412-7420 (2015).

44. Inamdar, S. M., Shinde, V. S. \& Patil, N. T. Enantioselective cooperative catalysis. Org. Biomol. Chem. 13, 8116-8162 (2015).

45. Shibasaki, M., Kanai, M., Matsunaga, S. \& Kumagai, N. Recent progress in asymmetric bifunctional catalysis using multimetallic systems. Acc. Chem. Res. 42, 1117-1127 (2009).

46. Matsunaga, S. \& Shibasaki, M. Recent advances in cooperative bimetallic asymmetric catalysis: dinuclear Schiff base complexes. Chem. Commun. 50, 1044-1057 (2014)

47. Li, J. et al. Bimetallic gold(I)/chiral N,N'-dioxide nickel(II) asymmetric relay catalysis: chemo- and enantioselective synthesis of spiroketals and spiroaminals. Angew. Chem. Int. Ed. 55, 6075-6078 (2016).

48. Li, J. et al. Gold(I)/chiral $N, N^{\prime}$-dioxide-nickel(II) relay catalysis for asymmetric tandem intermolecular hydroalkoxylation/Claisen rearrangement. Angew. Chem. Int. Ed. 56, 885-888 (2017).

49. Chen, Y. S., Dong, S. X., Xu, X., Liu, X. H. \& Feng, X. M. Bimetallic rhodium(II)/indium(III) relay catalysis for tandem insertion/asymmetric Claisen rearrangement. Angew. Chem. Int. Ed. 57, 16554-16558 (2018).

50. Zheng, H. F. et al. Diversified Cycloisomerization/Diels-Alder reactions of 1,6-enynes through bimetallic relay asymmetric catalysis. Angew. Chem. Int. Ed. 58, 5327-5331 (2019).

51. Ge, S. L. et al. Bimetallic catalytic asymmetric tandem reaction of $\beta$-alkynyl ketones to synthesize 6,6-spiroketals. Angew. Chem. Int. Ed. 58, 4017-4021 (2019).

52. Xu, J. X. et al. Enantioselective vinylogous Michael-Adole reaction to synthesize spirocyclohexene pyrazolones in aqueous media. Org. Lett. 21, 1632-1636 (2019).

\section{Acknowledgements}

We appreciate the National Natural Science Foundation of China (Nos. 21871188 and 21890723) for financial support.

\section{Author contributions}

X. H. performed the experiments. X. T. repeated data. X. Z. participated in the discussion. X. F. and L. L. supervised the project. X. F., L. L., and X. H. co-wrote the manuscript.

\section{Competing interests}

The authors declare no competing interests. 


\section{Additional information}

Supplementary information The online version contains supplementary material available at https://doi.org/10.1038/s41467-021-23105-z.

Correspondence and requests for materials should be addressed to L.L. or X.F.

Peer review information Nature Communications thanks Rui Shang and the other anonymous reviewers for their contribution to the peer review of this work. Peer reviewer reports are available.

Reprints and permission information is available at http://www.nature.com/reprints

Publisher's note Springer Nature remains neutral with regard to jurisdictional claims in published maps and institutional affiliations. (c) (P) Open Access This article is licensed under a Creative Commons Attribution 4.0 International License, which permits use, sharing, adaptation, distribution and reproduction in any medium or format, as long as you give appropriate credit to the original author(s) and the source, provide a link to the Creative Commons license, and indicate if changes were made. The images or other third party material in this article are included in the article's Creative Commons license, unless indicated otherwise in a credit line to the material. If material is not included in the article's Creative Commons license and your intended use is not permitted by statutory regulation or exceeds the permitted use, you will need to obtain permission directly from the copyright holder. To view a copy of this license, visit http://creativecommons.org/ licenses/by/4.0/.

(C) The Author(s) 2021 